\title{
Imaging Processes Using Core-Shell Particle Colloid Solutions for Medical Diagnosis
}

\author{
By Yoshio Kobayashi* \\ Kohsuke Gondat \\ Noriaki Ohuchi
}

\begin{abstract}
This paper describes our studies on development of methods for preparing colloid solutions of core-shell particles composed of core of materials with imaging ability and shell of silica that is inert to living bodies, and on their imaging properties. The methods for silica-coating are based on hydrolysis and condensation of silicone alkoxide in the presence of particles. AgI nanoparticles fabricated by mixing $\mathrm{AgClO}_{4}$ aqueous solution with $\mathrm{KI}$ aqueous solution were silica-coated with an aid of silane coupling agent. The silica-coated AgI particle colloid solution revealed X-ray imaging ability. Au nanoparticles, which were produced with reduction of $\mathrm{HAuCl}_{4}$ using citrate as reducing reagent and then surface-modified with silane coupling agent, were coated with silica. Images of the colloid solution were successfully taken through X-ray irradiation. For Gd compound, silica nanoparticles fabricated by a Stöber method were coated with Gd compound shell by a homogeneous precipitation method, and then coated with silica shell. The colloid solution was successfully imaged through magnetic resonance. Commerciallyavailable Cd-related semiconductor nanoparticles were surfacemodified with silane coupling agent, and then coated with silica. Tissues of mouse were imaged by injecting their colloid solution and using an in vivo fluorescence imaging system (IVIS).
\end{abstract}

\section{Introduction}

Performance of imaging processes using X-ray (Kim et al., 2010; Kitajima et al., 2012; Melendez-Ramirez et al., 2012), magnetic resonance (Secchi et al., 2011; Telgmann et al., 2013; Yu et al., 2013) and fluorescence (Savla et al., 2011; Mattoussi et al., 2012; Lira et al., 2012; Cassette et al., in press) in medical diagnosis can be improved with agents with imaging abilities that are so-called contrast agents. Various contrast agents are commercially available, and typical commercial contrast agents are solutions containing iodine compounds for X-ray imaging, Gd complexes for magnetic resonance imaging

${ }^{*}$ Professor, College of Engineering, Ibaraki University, Japan.

${ }^{\dagger}$ Professor, Graduate School of Medicine, Tohoku University, Japan.

${ }^{\ddagger}$ Professor, Graduate School of Medicine, Tohoku University, Japan. 
(MRI) and Cd compound nanoparticles or quantum dot (QD) for fluorescence imaging at molecular or nanometer levels. Metallic Au nanoparticles can also reveal X-ray imaging ability (Menk et al., 2011; Peng et al., 2012; Wang et al., 2013). These contrast agents are not strongly dragged in fluid because of their small sizes. Consequently, they cannot stay in living bodies for a long period, which provides difficulty taking steady images. Formation of particles of the contrast agents and an increase in apparent particle size are promising solutions to the problem, because of their projected area larger than molecules or nanoparticles, and consequently their residence time will increase. In addition, the contrast agents may cause adverse reactions derived from iodine (Zhao et al., 2011; Thomsen, 2011), metallic Au (Lasagna-Reeves et al., 2010; Cui et al., 2011; Schulz et al., 2012), Gd ions (Thomsen, 2011; Pietsch et al., 2011; Telgmann et al., 2013), and Cd (Kušić et al., 2012; Ambrosone et al., 2012; Soenen et al., 2012; Ma-Hock et al., 2012). Coating of the particles with shell inert to living bodies is a candidate for controlling the adverse reactions, since the particles cannot contact with living bodies. Our research group has recently studied on development of methods for preparing colloid solutions of coreshell particles composed of core of materials with imaging ability and shell of silica that is inert to living bodies, and on their imaging properties (Ayame et al., 2011; Kobayashi et al., 2007, 2010a, 2010b, 2011, 2012a, 2013a, 2013b). The methods used are based on hydrolysis and condensation of silicone alkoxide in the presence of particles such as iodine compound nanoparticless prepared by mixing $\mathrm{AgClO}_{4}$ aqueous solution with $\mathrm{KI}$ aqueous solution (Ayame et al., 2011; Kobayashi et al., 2012a), metallic Au nanoparticles prepared by reducing $\mathrm{HAuCl}_{4}$ with citrate (Kobayashi et al., 2011, 2013b), silica nanoparticles coated with $\mathrm{Gd}$ compound $(\mathrm{GdC})$ shell by a homogeneous precipitation method (Kobayashi et al., 2007), and commercially-available QD (Kobayashi et al., 2010a, 2010b, 2013a). The particle colloid solutions prepared revealed imaging abilities worthy of note. In this paper, we introduce our recent studies on them.

\section{Silica-coated AgI particles}

Several methods for coating nanoparticles with silica have been reported (Li et al., 2010; Darbandi et al., 2010; Bahadur et al., 2011; Wu et al., 2011). Most silica-coating methods reported are based on a Stöber method using silicon alkoxide as a silica source and amine as a catalyst. Since amines are harmful to living bodies, they are desired to be removed from the silica-coated particles. However, it is hard to remove them after preparation, because the amines should be distributed throughout the silica shell. Accordingly, methods with no use of amines are required as methods for producing the silica-coated particles. From this view point, our previous works proposed methods using sodium hydroxide $(\mathrm{NaOH})$ not amine for preparing various silica-coated particles (Ayame et al., 2011; Kobayashi et al., 2010c, 2011, 2012a, 2012b, 2012c, 2013a, 2013b; Morimoto et al., 2011; Sakurai et al., 2012). Our group 
has targeted AgI nanoparticles for silica-coating, since their colloid solution is easily prepared in aqueous solution. Thus, this section introduces an amine catalyst-free method for silica-coating of $\mathrm{AgI}$ nanoparticles $\left(\mathrm{AgI} / \mathrm{SiO}_{2}\right)($ Ayame et al., 2011; Kobayashi et al., 2012a, 2012c; Sakurai et al., 2012). A study on $\mathrm{X}$-ray imaging properties of the $\mathrm{AgI} / \mathrm{SiO}_{2}$ particles colloid solution is also introduced (Ayame et al., 2011; Kobayashi et al., 2012a).

$\mathrm{AgI}$ nanoparticles were prepared by mixing an $\mathrm{AgClO}_{4}$ aqueous solution and a $\mathrm{KI}$ aqueous solution at a $\left[\mathrm{AgClO}_{4}\right] /[\mathrm{KI}]$ molar ratio of $1 / 2$ under vigorous stirring at $20^{\circ} \mathrm{C}$. Immediately after the mixing, color of the solution turned yellow, which implied formation of AgI nanoparticles. To the obtained colloid solution of AgI nanoparticles were added an MPS aqueous solution, ethanol and tetraethylorthosilicate (TEOS). Then, the silica-coating was initiated by rapidly injecting an $\mathrm{NaOH}$ aqueous solution into the AgI/TEOS colloid solution. The reaction time was $24 \mathrm{~h}$. The obtained as-prepared $\mathrm{AgI} / \mathrm{SiO}_{2}$ particle colloid solution was concentrated by salting out the $\mathrm{AgI} / \mathrm{SiO}_{2}$ particles, removing the supernatant with decantation, adding water or saline to the residue, and shaking it with a vortex mixer. This concentrating process resulted in production of the colloid solution with an $\mathrm{AgI}$ concentration of $0.32 \mathrm{M}$ (concentrated $\mathrm{AgI} / \mathrm{SiO}_{2}$ particle colloid solution).

Figure 1 (a) shows a photograph of the concentrated $\mathrm{AgI} / \mathrm{SiO}_{2}$ particle colloid solution. A yellowish, milk-white colloid solution was obtained with no aggregation. Figure 1 (b) shows a transmittance electron microscope (TEM) image of the $\mathrm{AgI} / \mathrm{SiO}_{2}$ particles in the concentrated colloid solution. The particles had a size of $60.9 \pm 11.2 \mathrm{~nm}$, and contained the AgI nanoparticles with a size of $13.5 \pm 4.2 \mathrm{~nm}$. A CT value of the concentrated colloid solution was $2908 \pm 37$ HU. This value corresponded to that for Iopamiron ${ }^{\circledR} 300$, whose iodine concentration was adjusted to $0.59 \mathrm{M}$. This meant that though the AgI concentration value for the high concentration colloid solution was smaller than the iodine concentration of $0.59 \mathrm{M}$ for the concentration-adjusted Iopamiron ${ }^{\circledR} 300$, there was no difference in CT value between them. Since some of the excess $\mathrm{I}^{-}$were probably adsorbed on the AgI nanoparticles, an iodine concentration in the AgI particle colloid solution might be larger than the AgI concentration. Consequently, the high concentration colloid solution revealed the CT value larger than expected.

Figure 1. Photograph of the Concentrated $\mathrm{AgI} / \mathrm{SiO}_{2}$ Particle Colloid Solution (a), and TEM Image of the AgI/SiO ${ }_{2}$ Particles in the Concentrated Colloid Solution (b). Originated from J. Ceram. Soc. Jpn., 2011, 119, 397, with kind Permission from the Ceramic Society of Japan

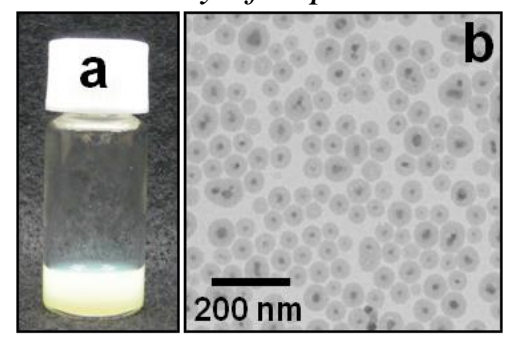


Figure 2 shows the X-ray images of the mice prior to and after the injection of the concentrated colloid solution. Prior to the injection, it was difficult to recognize tissues such as a liver and a spleen in the images. After the injection, these tissues were imaged with contrasts lighter than prior to the injection. This observation indicated that the $\mathrm{AgI} / \mathrm{SiO}_{2}$ particles reached efficiently at the tissues through a flow in blood tubes, and were trapped in the tissues, and then the tissues could be imaged, which promises that the $\mathrm{AgI} / \mathrm{SiO}_{2}$ particle colloid solutions can work as an X-ray contrast agent.

Figure 2. X-ray Images of (a-2) a liver and (b-2) a Spleen of a Mouse after Injection of the Concentrated $\mathrm{AgI} / \mathrm{SiO}_{2}$ Particle Colloid Solution. Images (a-1) and $(b-1)$ were taken Prior to the Injection. Originated from J. Ceram. Soc. Jpn., 2011, 119, 397, with kind Permission from the Ceramic Society of Japan

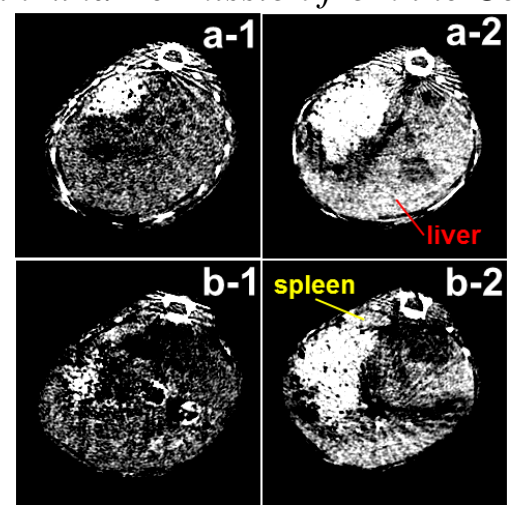

\section{Silica-coated Au Particles}

This section introduces an amine catalyst-free method for silica-coating of $\mathrm{Au}$ nanoparticles $\left(\mathrm{Au} / \mathrm{SiO}_{2}\right)$ (Kobayashi et al., 2011, 2012b, 2013b). Optical properties and $\mathrm{X}$-ray imaging properties of the $\mathrm{Au} / \mathrm{SiO}_{2}$ particle colloid solutions were also studied (Kobayashi et al., 2011, 2013b).

$\mathrm{Au}$ nanoparticles with an average size of $16.9 \mathrm{~nm}$ were prepared by reduction of $\mathrm{Au}$ salt with sodium citrate (Na-cit). A freshly prepared aqueous $\mathrm{Na}$-cit solution was added to an aqueous $\mathrm{HAuCl}_{4}$ solution at a constant temperature of $80^{\circ} \mathrm{C}$ under vigorous stirring. The color of the mixture turned wine red within a few minutes, which indicated the generation of $\mathrm{Au}$ nanoparticles. The Au nanoparticle colloid solution was added to $\mathrm{H}_{2} \mathrm{O}$ /ethanol solution. To the $\mathrm{Au} / \mathrm{H}_{2} \mathrm{O} /$ ethanol solution were added (3-aminopropyl) trimethoxysilane (APMS) dissolved in ethanol, TEOS/ethanol solution and $\mathrm{NaOH}$ aqueous solution, which produced $\mathrm{Au} / \mathrm{SiO}_{2}$ particle colloid solution. The reaction temperature and time were $35^{\circ} \mathrm{C}$ and $24 \mathrm{~h}$, respectively. The asprepared colloid solution was concentrated with salting-out and centrifugation up to $0.19 \mathrm{M} \mathrm{Au}$ (concentrated $\mathrm{Au} / \mathrm{SiO}_{2}$ ).

TEM observation revealed that the Au nanoparticles were coated with silica shell as well as the $\mathrm{AgI} / \mathrm{SiO}_{2}$ particles. Silica shell thickness could be varied from 6.0 to $61.0 \mathrm{~nm}$ by varying initial concentrations of TEOS and $\mathrm{NaOH}$. 
$\mathrm{Au} / \mathrm{SiO}_{2}$ particles prepared at $0.5 \times 10^{-3} \mathrm{M}$ TEOS and $0.5 \times 10^{-3} \mathrm{M} \mathrm{NaOH}$ had silica shell with a thickness of $15.2 \mathrm{~nm}$.

Figure 3 (c) shows a photograph of the concentrated $\mathrm{Au} / \mathrm{SiO}_{2}$ particle colloid solution. A dark wine-red colloid solution was obtained with no aggregation, which indicated that the particles were colloidally stable even at the $\mathrm{Au}$ concentration as high as $0.19 \mathrm{M}$. Figures 3 (a) and (b) show X-ray images of saline and the concentrated $\mathrm{Au} / \mathrm{SiO}_{2}$ particle colloid solution, respectively. The colloid solution exhibited a high contrast image with a white image of the backyard, compared with the saline. A CT value of the concentrated $\mathrm{Au} / \mathrm{SiO}_{2}$ particle colloid solution was as high as $1329.7 \pm 52.7 \mathrm{HU}$ at an Au concentration of $0.129 \mathrm{M}$, while that of a commercial X-ray contrast agent, Iopamiron $^{\circledR}$, was $680 \mathrm{HU}$ at an iodine concentration of $0.13 \mathrm{M}$. These measurements indicated that the $\mathrm{Au} / \mathrm{SiO}_{2}$ particle colloid solution obtained in the present work had X-ray imaging properties superior to the commercial agent with regard to the $\mathrm{CT}$ value.

Figure 3. X-ray Images of (a) Saline and (b) the concentrated $\mathrm{Au} / \mathrm{SiO}_{2}$ Particle Colloid Solution in Plastic Syringes. Image (c) shows a Photograph of the concentrated $\mathrm{Au} / \mathrm{SiO}_{2}$ Particle Colloid Solution obtained from the as-prepared $\mathrm{Au} / \mathrm{SiO}_{2}$ Particle Colloid Solution. Originated from J. Colloid Interface Sci., 2011, 358, 329, with kind Permission from Elsevier

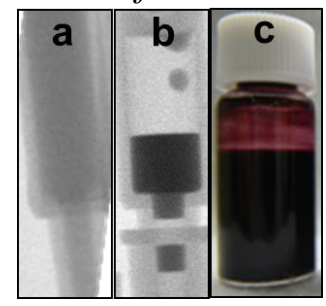

\section{Silica/Gd Compound/silica Multilayered Core-shell Particles}

Particles containing contrast agents must be colloidally stable, because particle aggregation causes restriction of blood flow and lymph flow. Since silica particles have good stability as colloids, three layered particles with silica core, layer of contrast agent and silica shell will be more stable than contrast agents without silica core. The silica core plays a role for stability of particles and the silica shell plays a role of insulation from outside the particle. This section introduces a method for producing the three multilayered particles, and a study on verification of their MRI ability (Kobayashi et al., 2007).

Core particles used were silica particles an average size of $31 \pm 4 \mathrm{~nm}$ (Figure 4 (a)), which were fabricated by a sol-gel method using TEOS, $\mathrm{H}_{2} \mathrm{O}$, methylamine (MA) and ethanol. GdC-coating of the silica particles was performed by a homogeneous precipitation method using $\mathrm{Gd}\left(\mathrm{NO}_{3}\right)_{3}$ and urea in propanol-water solution containing the silica particles and polyvinylpyrrolidone (PVP) at $80^{\circ} \mathrm{C}$ for $3 \mathrm{~h}\left(\mathrm{SiO}_{2} / \mathrm{GdC}\right)$. Silica-coating of the $\mathrm{SiO}_{2} / \mathrm{GdC}$ core-shell particles was performed by a sol-gel method using TEOS, $\mathrm{H}_{2} \mathrm{O}$, 
$\mathrm{NaOH}$ and ethanol $\left(\mathrm{SiO}_{2} / \mathrm{GdC} / \mathrm{SiO}_{2}\right)$. The obtained $\mathrm{SiO}_{2} / \mathrm{GdC} / \mathrm{SiO}_{2}$ particles were washed by repeating centrifugation, removal of supernatant, addition of the water and sonication over three times.

The colloid solution of $\mathrm{SiO}_{2} / \mathrm{GdC}$ particles exhibited no aggregation, which indicated that colloidal stability of silica core particles prevented generation of aggregation. Figure 4 (b) shows a scanning transmission electron microscope (STEM) image of $\mathrm{SiO}_{2} / \mathrm{GdC}$ particles. The silica particles were coated with uniform shell. The average particle size was $57 \pm 6 \mathrm{~nm}$. Sedimentation was observed in $24 \mathrm{~h}$ after preparation. Figure 4 (c) shows STEM image of multilayered $\mathrm{SiO}_{2} / \mathrm{GdC} / \mathrm{SiO}_{2}$ core-shell particles. Only multilayered core-shell particles were observed, and there was no core-free silica or shell-free $\mathrm{SiO}_{2} / \mathrm{GdC}$ particles. The $\mathrm{SiO}_{2} / \mathrm{GdC} / \mathrm{SiO}_{2}$ particles had an average size of $71 \pm 6 \mathrm{~nm}$. It was confirmed by naked eye that no sedimentation took place for the $\mathrm{SiO}_{2} / \mathrm{GdC}_{\mathrm{SiO}}$ particle colloid in $24 \mathrm{~h}$ after preparation. This observation indicated that the silica shell contributed to the colloidal stability. These formations of core-shell structures were supported by EDX analysis and XPS measurements.

Figure 4. Images of (a) Silica, (b) $\mathrm{SiO}_{2} / \mathrm{GdC}$ and (c) $\mathrm{SiO}_{2} / \mathrm{GdC}_{\mathrm{SiO}}$ Particles. The Image (a) was taken by TEM, and the Images $(b)$ and $(c)$ were taken by STEM. Originated from Colloids Surf. A, 2007, 308, 14, with kind Permission from Elsevier

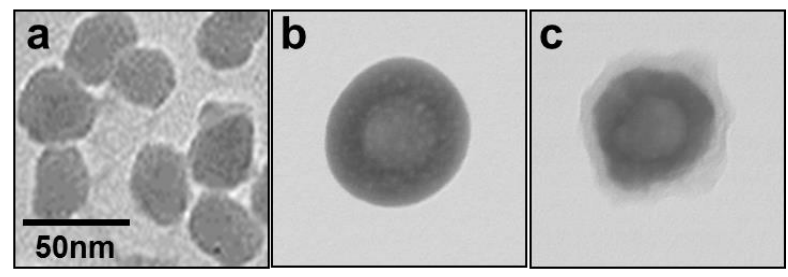

Figure 5 shows $\mathrm{T} 1$-weighted images of the $\mathrm{SiO}_{2} / \mathrm{GdC}$ and the $\mathrm{SiO}_{2} / \mathrm{GdC} / \mathrm{SiO}_{2}$ particles. For comparison, magnetic resonance (MR) signal intensity of water was also estimated. A T1-weighted image was faintly observed for the water. The $\mathrm{SiO}_{2} / \mathrm{GdC}$ and the $\mathrm{SiO}_{2} / \mathrm{GdC} / \mathrm{SiO}_{2}$ particles exhibited clear images. These results indicated that the colloid solution of $\mathrm{SiO}_{2} / \mathrm{GdC} / \mathrm{SiO}_{2}$ particles could function as the MRI contrast agent.

Figure 5.Tl-weighted Images of (a) Water, (b) $\mathrm{SiO}_{2} / \mathrm{GdC}$ and (c) $\mathrm{SiO}_{2} / \mathrm{GdC} / \mathrm{SiO}_{2}$ Particles. The Images were taken with $26 \mathrm{~ms}$ for the Echo Time and $800 \mathrm{~ms}$ for the Repetition Time at a Static Magnetic Field of $0.4 \mathrm{~T}$. Originated from Colloids Surf. A, 2007, 308, 14, with Kind Permission from Elsevier

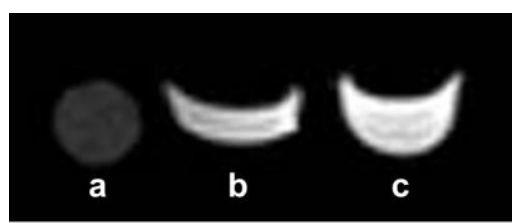




\section{Silica-coated Cd-related Semiconductor Particles}

Nanoparticles of Cd-related semiconductor such as CdS, CdSe and CdTe, which are called as QD, exhibit unique fluorescence properties different from their bulk materials. The fluorescence properties of QD are expected to be used in medical fields such as bioimaging, biosensing and drug delivery. The QD, however, faces at a problem in practical use, since cadmium is harmful for living bodies. Silica-coating is a good candidate for reducing the harm, as mentioned in the Introduction. This section introduces a method for producing $\mathrm{QD} / \mathrm{SiO}_{2}$ core-shell particles (Kobayashi et al., 2010a, 2010b, 2013 a), and a study on fluorescence imaging technique using their colloid solution (Kobayashi et al., 2013a).

QDs used as seed nanoparticles for silica-coating were Qdot ${ }^{\circledR}$ (Invitrogen Co.) with a catalogue number of Q21371MP. The QDs are $\mathrm{CdSe}_{\mathrm{x}} \mathrm{Te}_{1-\mathrm{x}}$ nanoparticles coated with $\mathrm{ZnS}$ and succeedingly surface-modified with carboxyl groups. According to TEM observation, the QDs had an average size of $10.3 \pm 2.2 \mathrm{~nm}$. To the colloid of QDs were added water/ethanol solution and successively TEOS/ethanol solution. Then, the silica-coating was initiated by rapidly injecting $\mathrm{NaOH}$ aqueous solution into the QD/TEOS colloid solution. The silica-coating was performed for $24 \mathrm{~h}$ at room temperature. The QD/SiO colloid solution was concentrated with a process composed of evaporation of solvent, centrifugation, removal of supernatant, addition of solvent, and redispersion (concentrated $\mathrm{QD} / \mathrm{SiO}_{2}$ colloid solution). An aqueous solution of methoxy polyethylene glycol silane (M-SLN-5000) (JenKem Technology Co., Ltd., Mn:5000) was added to the concentrated $\mathrm{QD} / \mathrm{SiO}_{2}$ particle colloid solution, in which poly(ethylene glycol) (PEG) was expected to be introduced on particle surface through a reaction between silanol groups on $\mathrm{QD} / \mathrm{SiO}_{2}$ particle surface and alkoxide groups of the M-SLN-5000. The QD/SiO $2 / \mathrm{PEG}$ colloid solution was concentrated with a process composed of centrifugation, removal of supernatant, addition of solvent, and redispersion.

TEM observation revealed that the QDs were coated with silica shell as well as the $\mathrm{AgI} / \mathrm{SiO}_{2}$ particles and the $\mathrm{Au} / \mathrm{SiO}_{2}$ particles. A particle size of the $\mathrm{QD} / \mathrm{SiO}_{2} / \mathrm{PEG}$ particles was ca. $50 \mathrm{~nm}$. Figures 6 (a)-(c) show photographs of mouse taken prior to and after injection of $\mathrm{QD} / \mathrm{SiO}_{2} / \mathrm{PEG}$ particle colloid solution, and their images taken in vivo fluorescence imaging system (IVIS). Fluorescence emission became strong as time passed since the injection. Figure 6 (d) shows a photograph and an IVIS image of the mouse after the injection and the following performance of laparotomy. Fluorescence emission from tissues was clearly observed, which indicated that the injected $\mathrm{QD} / \mathrm{SiO}_{2} / \mathrm{PEG}$ particles colloid solution reached at the tissues from the vein. 
Figure 6. Photographs (A) and IVIS images (B) of Mouse taken (a) Prior to, (b) at $5 \mathrm{~min}$ after, and (c) at $1 \mathrm{~h}$ after Injection of QD/SiO$/ P E G$ Particle Colloid Solution. The Mouse (d) was the Mouse (c), for which a Laparotomy was performed. Originated from J. Sol-Gel Sci. Technol., 2013, 66, 31, with Kind Permission from Springer

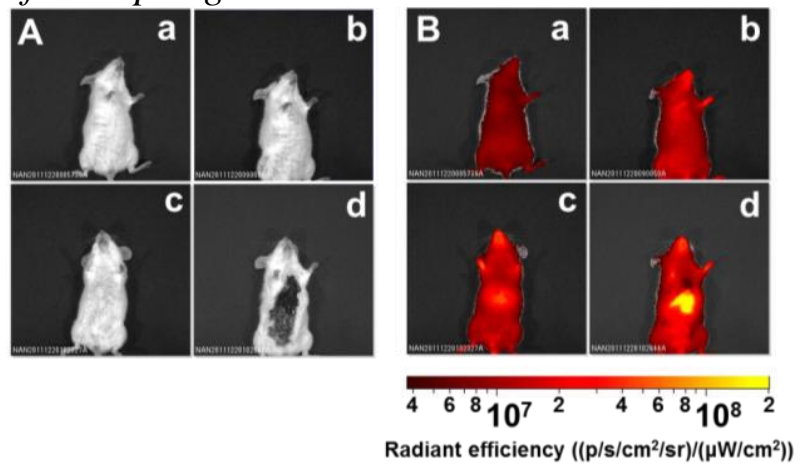

\section{Conclusions}

This paper introduced our recent studies on development of methods for silica-coating of particles with imaging ability with the sol-gel reaction of silicone alkoxide. The obtained silica-coated particle colloid solutions revealed various imaging properties. For X-ray imaging, the AgI nanoparticles and the Au nanoparticles were examined for silica-coating. The tissues of mouse were imaged with the use of the $\mathrm{AgI} / \mathrm{SiO}_{2}$ particle colloid solution. The $\mathrm{Au} / \mathrm{SiO}_{2}$ particle colloid solution had X-ray absorption higher than the commercial iodine-related X-ray contrast agent. For $\mathrm{GdC}$, the multilayered core-shell particles composed of silica core, GdC inner shell and silica outer shell were fabricated by combining the sol-gel method and homogeneous precipitation method. Their colloid solution was successfully imaged with the magnetic resonance process. For Cd-related semiconductor nanoparticles, the QDs were silica-coated with the aid of silane coupling agent. The $\mathrm{QD} / \mathrm{SiO}_{2}$ colloid solution could be applied to imaging of the tissues of mouse with the IVIS technique. Further study is in progress for practical use of the silica-coated particle colloid solutions.

\section{References}

Ambrosone, A., L. Mattera, V. Marchesano, A. Quarta, S.A .Susha, A. Tino, L.A. Rogach \& C. Tortiglione (2012). 'Mechanisms underlying toxicity induced by CdTe quantum dots determined in an invertebrate model organism.' Biomaterials 33: 1991-2000.

Ayame, T., Y. Kobayashi, T. Nakagawa, K. Gonda, M. Takeda \& N. Ohuchi (2011). 'Preparation of silica-coated AgI nanoparticles by an amine-free process and their X-ray imaging properties.' Journal of the Ceramic Society of Japan 119: 397-401. 
Bahadur, N.M., T. Furusawa, M. Sato, F. Kurayama, I.A. Siddiquey \& N. Suzuki (2011). 'Fast and facile synthesis of silica coated silver nanoparticles by microwave irradiation.' Journal of Colloid and Interface Science 355: 312-320.

Cassette, E., M. Helle, L. Bezdetnaya, F. Marchal, B. Dubertret \& T. Pons. 'Design of new quantum dot materials for deep tissue infrared imaging.'Advanced Drug Delivery Reviews in press.

Cui, W., J. Li, Y. Zhang, H. Rong, W. Lu \& L. Jiang (2012). 'Effects of aggregation and the surface properties of gold nanoparticles on cytotoxicity and cell growth.' Nanomedicine: Nanotechnology, Biology and Medicine 8: 46-53.

Darbandi, M., G. Urban \& M. Kruger (2010). 'A facile synthesis method to silica coated $\mathrm{CdSe} / \mathrm{ZnS}$ nanocomposites with tuneable size and optical properties.' Journal of Colloid and Interface Science 351: 30-34.

Kim, E.Y., T.S. Kim, J.Y. Choi, J. Han \& H. Kim (2010). 'Multiple tracheal metastases of lung cancer: CT and integrated PET/CT findings.' Clinical Radiology 65: 493-495.

Kitajima, K., Y. Ueno, K. Suzuki, M. Kita, Y. Ebina, H. Yamada, M. Senda, T. Maeda \& K. Sugimura (2012). 'Low-dose non-enhanced CT versus full-dose contrastenhanced CT in integrated PET/CT scans for diagnosing ovarian cancer recurrence $\therefore$ European Journal of Radiology 81: 3557-3562.

Kobayashi, Y., J. Imai, D. Nagao, M. Takeda, N. Ohuchi, A. Kasuya \& M. Konno (2007). 'Preparation of multilayered silica-Gd-silica core-shell particles and their magnetic resonance images.' Colloids and Surfaces A 308: 14-19.

Kobayashi, Y., T. Nozawa, M. Takeda, N. Ohuchi \& A. Kasuya (2010a). 'Direct silica-coating of quantum dots.' Journal of Chemical Engineering of Japan 43: 490-493.

Kobayashi, Y., T. Nozawa, T. Nakagawa, K. Gonda, M. Takeda, N. Ohuchi \& A. Kasuya (2010b). 'Direct coating of quantum dots with silica shell.' Journal of SolGel Science and Technology 55: 79-85.

Kobayashi, Y., M. Minato, K. Ihara, M. Sato, N. Suzuki, M. Takeda, N. Ohuchi \& A. Kasuya (2010c). 'Synthesis of silica-coated AgI nanoparticles and immobilization of proteins on them.' Journal of Nanoscience and Nanotechnology 10: 7758-7761.

Kobayashi, Y., H. Inose, T. Nakagawa, K. Gonda, M. Takeda, N. Ohuchi \& A. Kasuya (2011). 'Control of shell thickness in silica-coating of Au nanoparticles and their X-ray imaging properties.' Journal of Colloid and Interface Science 358: 329-333.

Kobayashi, Y., T. Ayame, T. Nakagawa, K. Gonda \& N. Ohuchi (2012). 'X-ray imaging technique using colloid solution of AgI/silica/poly(ethylene glycol) nanoparticles.' Materials Focus 1: 127-130.

Kobayashi, Y., H. Inose, T. Nakagawa, K. Gonda, M. Takeda, N. Ohuchi \& A. Kasuya (2012b). 'Synthesis of Au-silica core-shell particles by a sol-gel process.' Surface Engineering 28: 129-133.

Kobayashi, Y., M. Minato, K. Ihara, T. Nakagawa, K. Gonda, M. Takeda, N. Ohuchi \& A. Kasuya (2012c). 'Synthesis of high concentration colloid solution of silicacoated AgI nanoparticles.' Journal of Nanoscience and Nanotechnology 12: 67416745.

Kobayashi, Y., H. Matsudo, T. Nakagawa, Y. Kubota, K. Gonda, M. Takeda \& N. Ohuchi (2013a). 'In-vivo fluorescence imaging technique using colloid solution of multiple quantum dots/silica/poly(ethylene glycol) nanoparticles.' Journal of SolGel Science and Technology 66: 31-37. 
Kobayashi, Y., H. Inose, R. Nagasu, T. Nakagawa, Y. Kubota, K. Gonda \& N. Ohuchi (2013b). 'X-ray imaging technique using colloid solution of Au/silica/poly (ethylene glycol) nanoparticles.' Materials Research Innovations.

Kušić, H, D. Leszczynska (2012). 'Altered toxicity of organic pollutants in water originated from simultaneous exposure to UV photolysis and $\mathrm{CdSe} / \mathrm{ZnS}$ quantum dots.' Chemosphere 89: 900-906.

Lasagna-Reeves, C., D. Gonzalez-Romero, M.A. Barria, I. Olmedo, A. Clos, V.M. Sadagopa Ramanujam, A. Urayama, L. Vergara, M.J. Kogan \& C. Soto (2010). 'Bioaccumulation and toxicity of gold nanoparticles after repeated administration in mice.' Biochemical and Biophysical Research Communications 393: 649-655.

Li, Y.S., J.S. Church, A.L. Woodhead \& F. Moussa (2010). 'Preparation and characterization of silica coated iron oxide magnetic nano-particles.' Spectrochimica Acta Part A 76: 484-489.

Lira, B.R., B.M. Cavalcanti, A.B.L.M. Seabra, C.N.D. Silva, J.A. Amaral, S.B. Santos \& A. Fontes (2012). 'Non-specific interactions of $\mathrm{CdTe} / \mathrm{Cds}$ quantum dots with human blood mononuclear cells.' Micron 43: 621-626.

Ma-Hock, L., S. Brill, W. Wohlleben, A.M.P. Farias, R.C. Chaves, A.L.P.D. Tenorio, A. Fontes, S.B. Santos, R. Landsiedel, V. Strauss, S. Treumann \& V.B. Ravenzwaay (2012). 'Short term inhalation toxicity of a liquid aerosol of $\mathrm{CdS} / \mathrm{Cd}(\mathrm{OH})_{2}$ core shell quantum dots in male wistar rats.' Toxicology Letters 208: 115-124.

Mattoussi, H., G. Palui \& B.N. Hyon (2012). 'Luminescent quantum dots as platforms for probing in vitro and in vivo biological processes.' Advanced Drug Delivery Reviews 64: 138-166.

Melendez-Ramirez, G., F. Castillo-Castellon, N. Espinola-Zavaleta, A. Meave \& E.T. Kimura-Hayama (2012). 'Left ventricular noncompaction: A proposal of new diagnostic criteria by multidetector computed tomography.' Journal of Cardiovascular Computed Tomography 6: 346-354.

Menk, R.H., E. Schültke, C. Hall, F. Arfelli, A. Astolfo, L. Rigon, A. Round, K. Ataelmannan, S.R. MacDonald \& B.H.J. Juurlink (2011). 'Gold nanoparticle labeling of cells is a sensitive method to investigate cell distribution and migration in animal models of human disease.' Nanomedicine: Nanotechnology, Biology and Medicine 7: 647-654.

Morimoto, H., M. Minato, T. Nakagawa, M. Sato, Y. Kobayashi, K. Gonda, M. Takeda, N. Ohuchi \& N. Suzuki (2011). 'X-ray imaging of newly-developed gadolinium compound/silica core-shell particles.' Journal of Sol-Gel Science and Technology 59: 650-657.

Peng, C., L. Zheng, Q. Chen, M. Shen, R. Guo, H. Wang, X. Cao, G. Zhang \& X. Shi (2012). 'PEGylated dendrimer-entrapped gold nanoparticles for in vivo blood pool and tumor imaging by computed tomography.' Biomaterials 33: 1107-1119.

Pietsch, H., G. Jost, T. Frenzel, M. Raschke, J. Walter, H. Schirmer, J. Hutter \& M.A. Sieber (2011). 'Efficacy and safety of lanthanoids as X-ray contrast agents.' European Journal of Radiology 80: 349-356.

Sakurai, Y., H. Tada, K. Gonda, M. Takeda, L. Cong, M. Amari, Y. Kobayashi, M. Watanabe, T. Ishida \& N. Ohuchi (2012). 'Development of silica-coated silver iodide nanoparticles and their biodistribution.' The Tohoku Journal of Experimental Medicine 228: 317-323.

Savla, R., O. Taratula, O. Garbuzenko \& T. Minko (2011). 'Tumor targeted quantum dot-mucin 1 aptamer-doxorubicin conjugate for imaging and treatment of cancer.' Journal of Controlled Release 153: 16-22. 
Schulz, M., L. Ma-Hock, S. Brill, V. Strauss, S. Treumann, S. Gröters, B. van Ravenzwaay \& R. Landsiedel (2012). 'Investigation on the genotoxicity of different sizes of gold nanoparticles administered to the lungs of rats. ' Mutation Research 745: 51-57.

Secchi, F., G.D. Leo, G.D.E. Papini, F. Giacomazzi, M.D. Donato \& F. Sardanelli (2011). 'Optimizing dose and administration regimen of a high-relaxivity contrast agent for myocardial MRI late gadolinium enhancement.' European Journal of Radiology 80: 96-102.

Soenen, J.S., J. Demeester, D.C.S. Smedt \& K. Braeckmans (2012). 'The cytotoxic effects of polymer-coated quantum dots and restrictions for live cell applications.' Biomaterials 33: 4882-4888.

Telgmann, L., M. Sperling \& U. Karst (2013). 'Determination of gadolinium-based MRI contrast agents in biological and environmental samples: A review.' Analytica Chimica Acta 764: 1-16.

Thomsen H.S. (2011). 'Contrast media safety - An update.' European Journal of Radiology 80: 77-82.

Wang, H., L. Zheng, C. Peng, M. Shen, X. Shi \& G. Zhang (2013). 'Folic acidmodified dendrimer-entrapped gold nanoparticles as nanoprobes for targeted CT imaging of human lung adencarcinoma.' Biomaterials 34: 470-480.

Wu, Z., J. Liang, X. Ji \& W. Yang (2011). 'Preparation of uniform $\mathrm{Au@SiO} \mathrm{S}_{2}$ particles by direct silica coating on citrate-capped Au nanoparticles.' Colloids and Surfaces A 392: 220-224.

Yu, S.M., S.H. Choi, S.S. Kim, E.H. Goo, Y.S. Ji \& B.Y. Choe (2013). 'Correlation of the R1 and R2 values of gadolinium-based MRI contrast media with the $\Delta$ Hounsfield unit of CT contrast media of identical concentration.' Current Applied Physics 13: 857-863.

Zhao, Y., Z. Tao, Z. Xu, Z. Tao, B. Chen, L. Wang, C. Li, L. Chen, Q. Jia, E. Jia, T. Zhu \& Z. Yang (2011). 'Toxic effects of a high dose of non-ionic iodinated contrast media on renal glomerular and aortic endothelial cells in aged rats in vivo.' Toxicology Letters 202: 253-260. 
